\title{
Impact of Eccentricity and Demagnetization Faults on Magnetic Noise Generation in Brushless Permanent Magnet DC Motors
}

\author{
Ali Rezig ${ }^{\dagger}$, Mohammed Rachid Mekideche* and Abdesslem Djerdir**
}

\begin{abstract}
Vibrations and noise in electrical machines are directly related to the characteristics of the radial forces on one hand, and mechanical behavior on the other [1, 4]. The characteristics of these forces depend on the air gap flux density, which is also influenced by other factors, such as stator slots and poles, saturation level, winding type, and certain faults. The aim of this work is to investigate the effect of eccentricity and demagnetization faults on electromagnetic noise generated by the external surface of Permanent Magnet Synchronous Machine [PMSM]. For this purpose, an analytical electromagnetic vibroacoustic model is developed. The results confirm the effect of eccentricity and demagnetization fault in generating some low modes radial forces.
\end{abstract}

Keywords: Rotor eccentricity, Demagnetization, Noise and vibration, Radial magnetic force, Mode of vibration, Natural frequency, Acoustic radiation efficiency, Noise spectrum.

\section{Introduction}

Brushless direct current (BLDC) motors comprise one of the motor types that are rapidly gaining popularity. As the name implies, BLDC motors do not use brushes for commutation; instead, they are electronically commutated. BLDC motors have many advantages over brushed DC motors and induction motors [5]. These motors are used in many applications, such as traction with variable speeds in transportation. However, the operation of theses motors is accompanied by unavoidable production of noise especially in the presence of faults. Several works about noise and vibration of PM motors have been published in recent years [1], [3], [4]. However less research has been conducted on the vibroacoustic behavior of these motors in relation with faults and demagnetization [2].

The major contribution of this current research is the identification of the effects of rotor faults, such as eccentricities and demagnetization rotor magnet, which create fault signature in the motor sound power level spectrum. For this purpose, an analytical electromagnetic vibroacoustic approach to calculate the sound power level radiated from the PM motor is presented. To investigate the effect of eccentricity and demagnetization faults on magnetic noise, we introduce the two phenomena in the calculation of magnetic flux density in the air gap. The effect of eccentricity is introduced through the expression of the relative permeance, while the effect of demagnetization is introduced by modeling the field created by the rotor magnets

$\dagger \quad$ Corresponding author: Department of Electrical Engineering, Batna University, Algeria. (alirezikdz@yahoo.fr)

* Department of Electrical Engineering, Jijel University, Algeria.

** SeT Laboratory University of Belfort Montbéliard, France. (abesslem.djerdir@utbm.fr)

Received: May 13, 2010; Accepted: November 4, 2010 in the presence of a partial demagnetization defect. Analytically, the magnetic flux density in the air gap of PM brushless machine is the product of magnetic flux density generated by rotor magnet (or stator winding) as well as the relative permeance, which takes into account the effect of slots [6], [7] once the model calculates the natural frequency of the stator and frame, the stator yoke and frame displacements corresponding to the frequency of forces, and the noise in the surrounding medium. All parts of the analytical model are validated by finite elements method FEM simulations, allowing us to adjust and improve the analytical model.

\section{Air Gap Magnetic Flux Density and Radial Force Waves}

Analytically, the magnetic flux density in the air gap of PM brushless machine is the product of magnetic flux density generated by the rotor magnet (or stator windings) as well as the relative permeance functions that take into account the effect of slots and eccentricity faults given by:

$$
\begin{aligned}
& B(\theta, t)=\left[B_{\text {magnet }}(\theta, t)+B_{w}(\theta, t)\right] \bar{\lambda}(\theta), \\
& =B_{\text {open_circuit }}(\theta, t)+B_{a r}(\theta, t)
\end{aligned}
$$

where $B_{\text {magnet }}(\theta, t)$ and $B_{w}(\theta, t)$ are the open circuit fields produced by the magnet and stator windings, respectively, when the stator slotting is neglected. Both $B_{\text {magnet }}(\theta, t)$ and $B_{w}(\theta, t)$ can be calculated analytically from $2 \mathrm{D}$ models in polar coordinates. $\bar{\lambda}(\theta)$ is relative permeance, which takes into account the effect of slots [2]. In practice and for most PM, brushless motor harmonics in 
open circuit magnetic field play a dominant role in the noise of electromagnetic origin [1], [2]. Open circuit field calculated for a 600-Watt, 4-pole, 24-slot brushless motor is performed by analytical model and validated using FEM simulations. The results are presented in Fig. 1.
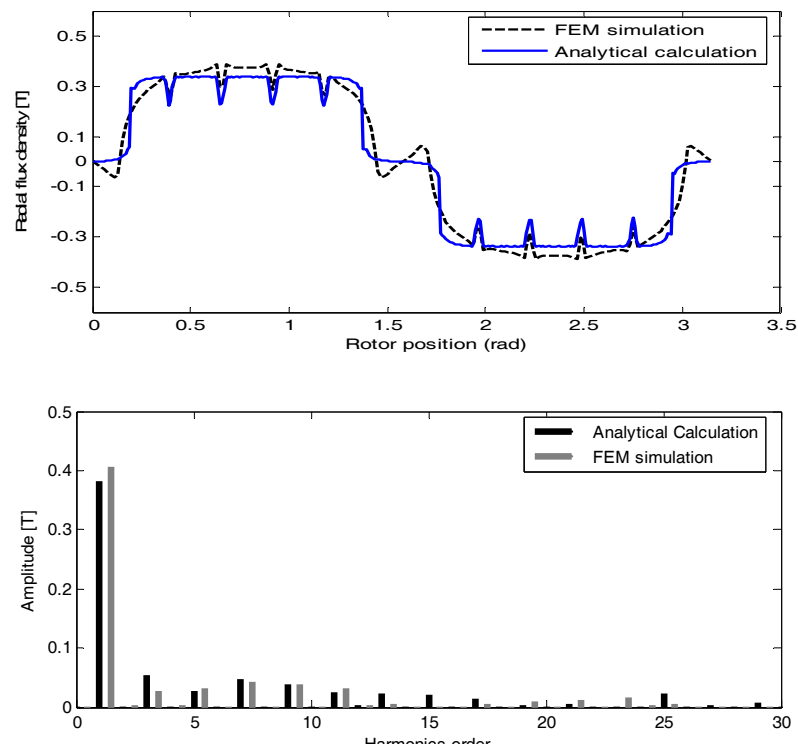

Fig. 1. Magnetic flux density in the air gap and its FFT decomposition

In a typical machine with unsaturated conditions, the flux lines are perpendicular to the iron surface. Therefore, the tangential component of flux density can be neglected. The radial pressure between stator and rotor surfaces can be written as [1], [2], [4]:

$$
\begin{gathered}
P_{r}=\frac{B^{2}(\theta, t)}{2 \mu_{0}} \text { and } \\
P_{r}=\frac{\left[B_{\text {magnet }}{ }^{2}(\theta, t)+2 B_{w}(\theta, t) B_{\text {magnet }}(\theta, t)+B_{w}{ }^{2}(\theta, t)\right] \bar{\lambda}(\theta)^{2}}{2 \mu_{0}} .
\end{gathered}
$$

In Eq. (3), there are three groups of infinite numbers of radial forces waves, and each force wave can be expressed in the following general form:

$$
P_{r}(\theta, t)=P_{m r} \cos \left(r \theta-w_{r} t-\theta_{r}\right),
$$

where Pmr is the amplitude of the magnetic pressure, wr is the angular frequency, and $\mathrm{r}=0,1,2,3,4 \ldots$ are the corresponding modes of radial magnetic force.

By only considering the pure circumferential vibration modes of the stator core, the deflection of stator core is an inverse function of the fourth power of the force order $r$. Thus, the most important factor from the airborne noise point of view is low circumferential mode number. Faults such as eccentricity and demagnetization of permanent magnet in PM brushless DC motors contribute to the generation of low mode vibration. The magnetic field calculated above in the case of faults contains additional harmonics that give rise to others harmonics forces waves.

\section{Rotor Eccentricity Faults}

In an ideal machine, the rotor is center-aligned with the stator bore, and the rotor's center of rotation is the same as the geometric center of the stator bore [Fig. 2]. A rotor eccentricity is a condition of unequal air gap that exists between the stator and the rotor. Air-gap eccentricity can occur in the form of static or dynamic eccentricity. In the case of a static eccentricity, the position of the minimum radial air-gap length is fixed in space.

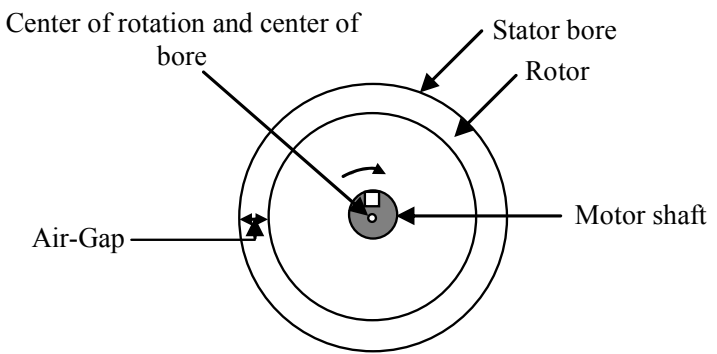

Fig. 2. Ideal motor (no-eccentric air-gap) Magnetic flux

The typical cause of static eccentricity includes stator core ovality or incorrect positioning of the rotor or the stator at the commissioning stage. A dynamic eccentricity occurs when the center of the rotor is not at the center of rotation, and the minimum air gap revolves with the rotor. This means that a dynamic eccentricity is a function of space and time. A typical cause of a dynamic eccentricity includes bent shafts, mechanical resonances at critical speed levels, and bearing wear.

Fig. 3 shows an illustration of how the rotor rotates in the presence of each type of air-gap eccentricity. Eccentricity faults in PM motors affect certain characteristic frequency components in the machine air-gap magnetic field and consequently vibration as well as the sound power

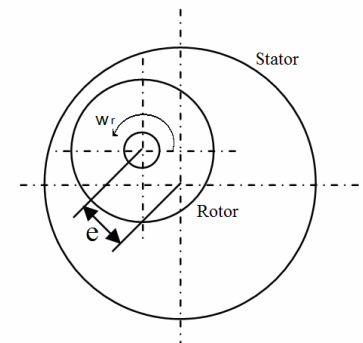

(a)

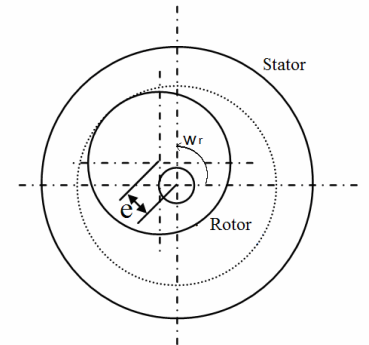

(b)
Fig. 3. Rotor eccentricities of (a) static and (b) dynamic eccentricities 
level spectrum radiated from the machine.

The dynamic eccentricity causes magnetic flux density component at a frequency given by:

$$
f_{d e}=f_{1}+k \frac{f_{e}}{p}
$$

where $f_{d e}$ is the dynamic eccentricity frequency, $f_{1}$ is the fundamental frequency, $p$ is the pole pair number, and $\mathrm{k}$ is any integer. The proof of Eq. (5) is based on the fact that the eccentricities cause change in the permeance. As indicated in Eq. (1), the flux density in the air-gap is given by the product of the field created by magnet (stator winding) and the relative air-gap permeance. Under the initial modelling assumption, the permeance is constant because of the uniform air gap. However, any change in the air-gap length causes a variation of the permeance, which can then be accounted for by additional harmonics in the permeance function and, consequently, in the air-gap magnetic field and radial magnetic forces.

In the mathematical model, the effect of eccentricity is accounted for by modifying the expression of the permeance function in Eq. (1), which becomes a variable in both space and time given by:

$$
\bar{\lambda}(\theta, t)=\bar{\lambda}_{s l}(\theta) \bar{\lambda}_{\text {eccs }}(\theta) \bar{\lambda}_{\text {eccd }}(\theta, t),
$$

where $\lambda_{s l}(\theta)$ is the relative permeance, which includes the stator slots openings [1]; and $\bar{\lambda}_{\text {eccs }}(\theta)$ and $\bar{\lambda}_{\text {eccd }}(\theta, t)$ are the relative permeance values including the static and dynamic eccentricity, respectively, and can be approximated by sinusoidal variation [1], [2].

For small eccentricities, $e<0.5 g$, the air gap can be expressed as a function of the angular displacement

$\alpha$, given by:

$$
g(\theta, t)=R-r-e \cos \left(\theta-w_{\varepsilon} t\right)=g\left[1-\varepsilon_{s, d} \cos \left(\theta-w_{\varepsilon} t\right)\right] .
$$

For uniform air gap the eccentricity, $e=0$, and the air gap

$$
g(\theta)=g=R-r,
$$

where

$R:$ the inner radius of the stator;

$r$ : the outer radius of the rotor; and

for static eccentricity,

$$
w_{\varepsilon}=0 \text { and }
$$

for dynamic eccentricity;

$$
w_{\varepsilon}=w=\frac{w}{p}=2 \pi \frac{f}{p} \text { and }
$$

$$
\varepsilon_{s, d}=\frac{e_{s, d}}{g} .
$$

Therefore, the permeance of the gap can be written as follows:

$$
\Lambda_{e c s, d}(\theta, t)=\frac{\mu_{0}}{g(\theta, t)}=\frac{\mu_{0}}{g\left[1-\varepsilon_{s, d} \cos \left(\theta-w_{\varepsilon} t-\phi_{\varepsilon}\right)\right]} .
$$

The expression ( ) can be transformed into the Fourier series as follows:

$$
\begin{aligned}
& A_{e c s, d}(\theta, t)=\frac{\mu_{0}}{g\left[1-\varepsilon_{s, d} \cos \left(\theta-v_{\varepsilon} t-\phi_{\varepsilon}\right]\right.}=\frac{\mu_{0}}{g} \lambda_{e c s, d}(\theta, t) \\
& =\lambda_{0, e s}+\sum_{k}\left[\lambda_{c k} \cos \left(w_{e} t-k \theta\right)+\lambda_{s k} \sin \left(w_{e} t-k \theta\right)\right]
\end{aligned},
$$

where:

$$
\begin{aligned}
& \lambda_{0, e s}=\frac{1}{2 \pi} \int_{-\pi}^{\pi} \frac{1}{1-\cos (\theta)} d \theta=\frac{1}{\sqrt{1-\varepsilon_{s, d}^{2}}} \text { and } \\
& \lambda_{c 1}=\frac{1}{\pi} \int_{-\pi}^{\pi} \frac{\cos (\theta)}{1-\varepsilon_{s, d} \cos (\theta)} d \theta \approx 2 \frac{1-\sqrt{1-\varepsilon^{2}}}{\varepsilon_{s, d} \sqrt{1-\varepsilon^{2}}} .
\end{aligned}
$$

Then, generally:

$$
\bar{\lambda}_{e c c s, d}(\theta, t)=\left[\frac{1}{\sqrt{1-\varepsilon_{s, d}^{2}}}+\sum_{k} 2\left(\frac{1-\sqrt{1-\varepsilon_{s, d}^{2}}}{\varepsilon \sqrt{1-\varepsilon_{s, d}^{2}}}\right)^{k} \cos \left(w_{e} t-k \theta\right)\right] .
$$

Further, including only the first term of the Fourier series, $e_{s}$ and $e_{d}$ are the static and dynamic eccentricities, respectively, and $g$ the air-gap length.

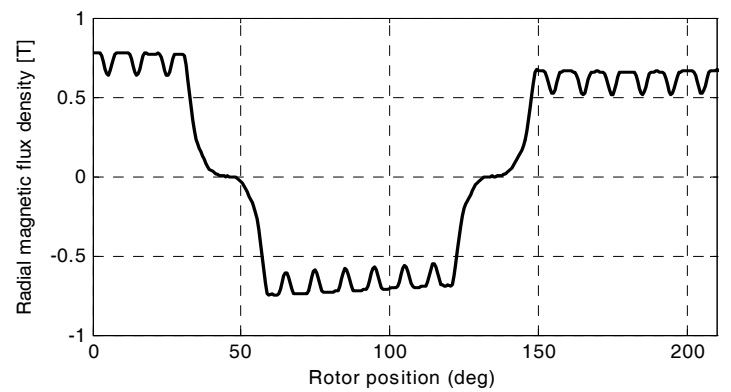

Fig. 4. Air-gap magnetic flux density with $25 \%$ eccentricity

Including Eq. (6) for air-gap permeance function instead of $\bar{\lambda}(\theta)$ in Eq. (1), we can obtain the magnetic flux density in the air gap of the machine while taking into account the eccentricity effect. Fig. 4 show the variation of mag- 
netic flux densities of 4 poles and 36 slots motors

\section{Rotor Demagnetization Faults}

An air gap flux disturbance resulting from some anomaly of permanent magnet is also an important fault occurring requently in BLDC motors. It is well known that some permanent magnet (Nd-Fe-B) corrodes and can lead to disintegration. The cracks that form during manufacturing can lead to disintegration at high speeds. The flux disturbances can also be caused by partial demagnetization of the magnets which occur for various reasons [5]. In this work, we are particularly interested in the partial demagnetization of the permanent magnet. Unsymmetrical magnetization fault (or partial demagnetization) affects the vibroacoustic behavior of the PM machine by introducing even order harmonics in air gap magnetic flux density.

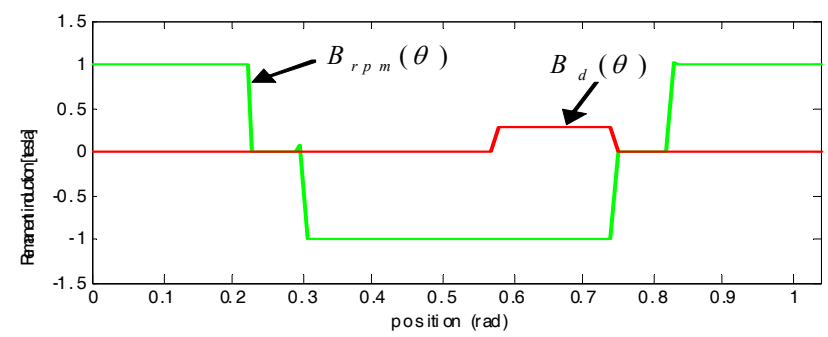

Fig. 5. The two components of the studied permanent magnet (Brpm: residual induction; Bd : fault signal)

To take into account the demagnetization effect in our model, the remanent induction was considered in the radial direction. The superposition theorem allowed us to consider the total induction of the permanent magnet containing a demagnetization phenomenon as consisting of two signals, in which Brpm represents the residual induction of the permanent magnet, and $\mathrm{Bd}$ represents the fault due to the demagnetization [9] (Fig. 5).

After decomposition in the Fourier series of two signals, the model calculates the magnetic induction in the air gap of the machine in the presence of the defect by solving the electromagnetic equation. In the case of defect, one notices the appearance of the harmonics of even order in the space FFT of induction, particularly the harmonic of order 2 which gives rise to the mode of vibration 2 . This is a very dangerous phenomenon from a vibroacoustic point of view. After calculating the magnetic field with faults (eccentricity or demagnetization) in the air gap of PM motor and according to Eqs. (3) and (4), we have an infinite number of radial magnetic forces waves in the air gap. These forces propagate in the air gap of the machine, producing deflexion of the stator yoke in radial direction and, consequently, noise in the surrounding medium. An engineering approach to prediction of noise is presented in the next section.

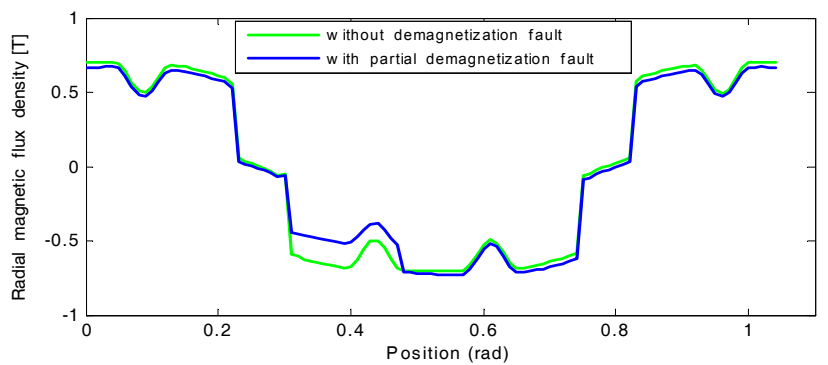

(a)

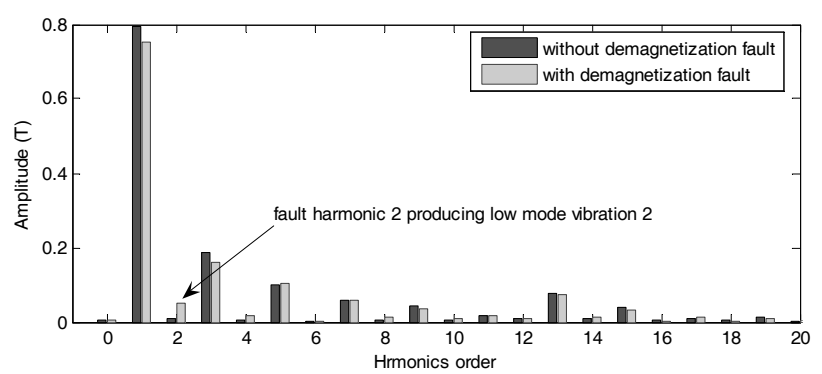

(b)

Fig. 6. Magnetic flux density in the air-gap with and without demagnetization (a) and its FFT decomposition (b)

\section{Prediction of Noise Radiated From the Stator System}

The electromagnetic part of the model described above allows us to have magnitudes, frequencies, and orders of radial magnetic forces. The noise and vibration of the motor structure are the direct responses of the excitation by these forces. For example, significant vibration and acoustic can be produced if the radial magnetic force is close to one of the natural frequencies of the stator system, and if the order $r$ is the same as the circumferential vibrational mode $\mathrm{m}$ of the stator system. The calculation of stator vibration, which is considered in this case as $2 \mathrm{D}$ ring with free boundary condition, is based on the theory of forced vibration with periodic excitation [11].

The vibration displacement of the machine of the mode number and frequency concerned can be derived as:

$$
Y_{d}^{m}=\frac{\pi D_{\text {\&in }} L_{i} P_{m r}}{K_{m}} \frac{1}{\sqrt{\left(1-f_{r}^{2} / f_{m}^{2}\right)^{2}+4 \zeta_{m}^{2} f_{r}^{2} / f_{m}^{2}}} .
$$

The vibration velocity of mode number $m$ is expressed as:

$$
V_{m}=2 \pi f_{r} Y_{d}^{m},
$$

where $D_{\text {lin }}$ is the stator core inner diameter, $L_{i}$ is the effective length of the stator core, $\mathrm{Km}$ is lumped stiffness of the stator, $\mathrm{fm}$ is the natural frequency of mode $\mathrm{m}, f_{r}$ is the 
frequency of the force component of the order $\mathrm{r}$, and $\zeta_{m}$ is the modal damping ration. The natural frequency of the stator system can be approximately evaluated as [1]:

$$
f_{m n}=\frac{1}{2 \pi} \sqrt{\frac{K_{m}^{(c)}+K_{m n}^{(f)}+K_{m}^{(w)}}{M_{c}+M_{f}+M_{w}}},
$$

where $K_{m}^{(c)}$ is the lumped stiffness of the stator core for the mth circumferential mode, $K_{m n}^{(f)}$ is the lumped stiffness of the frame for the mth circumferential and the nth axial mode, $K_{m}^{(w)}$ is lumped stiffness of the stator winding of $\mathrm{mth}$ circumferential vibrational mode, Mc is the lumped mass of the stator core, $\mathrm{Mf}$ is the lumped mass of the stator core, and $\mathrm{Mw}$ is lumped mass stator winding. A numerical validation of analytical calculation of natural frequency was made using COMSOL. Figs. 7 and 8 show how the stator machine is deformed when the vibration modes 3 and 4 are excited, respectively. The vibrating structure of the machine produces sound waves in the ambient medium. Given the outside dimensions of a PM machine, the radiated acoustic power $\mathrm{W}$ corresponding to a specific vibration component can be calculated from the relative sound intensity $\sigma_{m}(f)$, since:

$$
W_{m}(f)=\frac{1}{2} \rho_{0} c_{0} S_{c} \sigma_{m}(f) V_{m}^{2}
$$

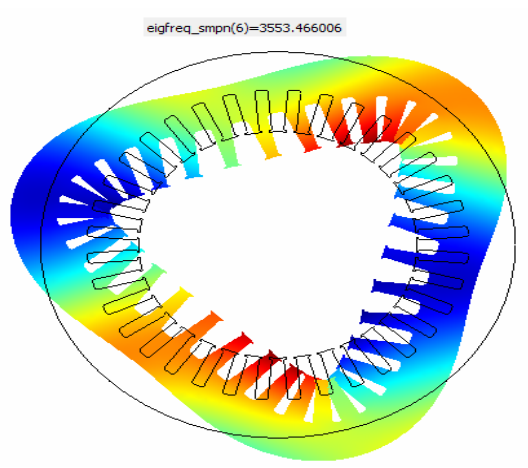

Fig. 7. Order 3 mode of PMSM

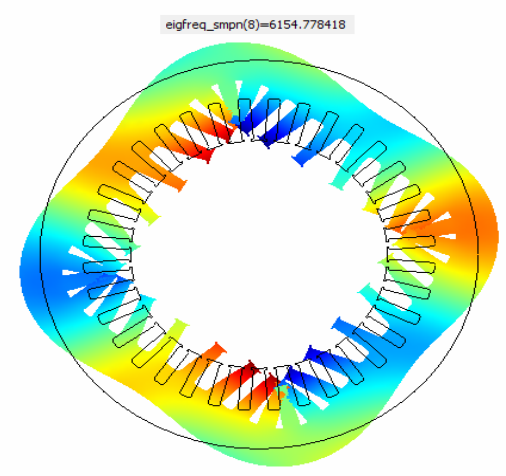

Fig. 8. Order 4 mode of PMSM where $S c$ is the stator outer surface, and $\rho_{0}$ the air density. Higher vibration levels mean higher radiated sound power. In many cases, however, it is not the absolute value, but $\sigma_{m}(f)$, which plays the role of transfer function from the structural vibration to the acoustic response that is of greatest interest. In addition, $\sigma_{m}$ is approximated using either its pulsating sphere expression and its finite or infinite cylindrical expression according to stator dimensions [10].

\section{Simulations Results of Sound Powel Level with Faults}

\subsection{Eccentricity Faults}

Three simulations were made for 4-pole, 36-slot PM synchronous motors at no load. The inner diameter was D1 in $=165 \mathrm{~mm}$, the stator outer diameter D1 out $=232.5 \mathrm{~mm}$, the effective length of stator was $170 \mathrm{~mm}$, and the air-gap $\mathrm{g}=1 \mathrm{~mm}$. In the first simulation, the rotor eccentricity was set at $0 \%$, while the motor speed was set at $3500 \mathrm{rpm}$. In the second simulation, the rotor eccentricity was set at $25 \%$ and speed was set to $3500 \mathrm{rpm}$. In the last simulation, the eccentricity was kept at $25 \%$ but the rotation speed was increased to $4200 \mathrm{rpm}$ in order to show the effect of the rotating speed.

Note that the natural frequency of the stator system, including the stator teeth and frame calculated analytically and validated numerically were: $5566 \mathrm{~Hz}$ for circumferential mode $0,991 \mathrm{~Hz}$ for circumferential mode $2,2671 \mathrm{~Hz}$ for circumferential mode 3 , and $4819 \mathrm{~Hz}$ for circumferential mode 4 . For a $0 \%$ eccentricity (symmetric condition), there were only modes 0,4 , and 8 . In the magnetic noise spectra for $25 \%$ eccentricity, some additional modes of vibration were introduced, including modes 3 and 5. In addition, rotational speed affected both the frequencies and magnitudes of the sound power level.

The eccentricity fault may be very dangerous when the motor is used in variable speed applications. This is because the frequency of force waves generated by eccentricity may become close to natural frequencies of vibration modes 3 and 5, and the contribution of this mode to the global sound radiated by the machine is very important [Fig. 12]. Further, the increase of total sound power level by $3 \mathrm{~dB}$ corresponded to an increase of sound power with double.

\subsection{Demagnetization Faults}

The demagnetization of the magnet was introduced in the analytical calculation of the field using the method described above for the same machine. Fig. 13 presents the noise spectrum radiated from the external surface of the machine, when the machine is subject to partial demagnetization on one of its magnet. From the Figure, and by com- 


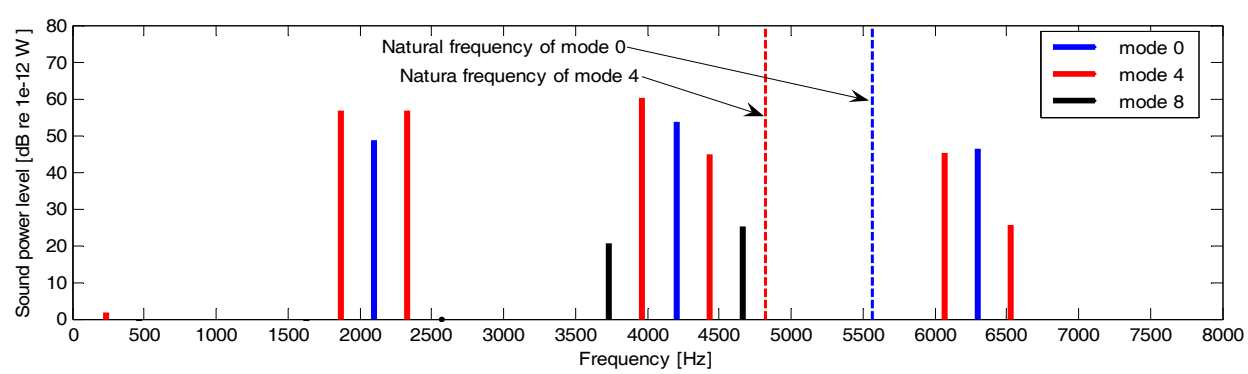

Fig. 9. Sound power level spectrum at $3500 \mathrm{rpm}$ and without eccentricity (symmetric condition)

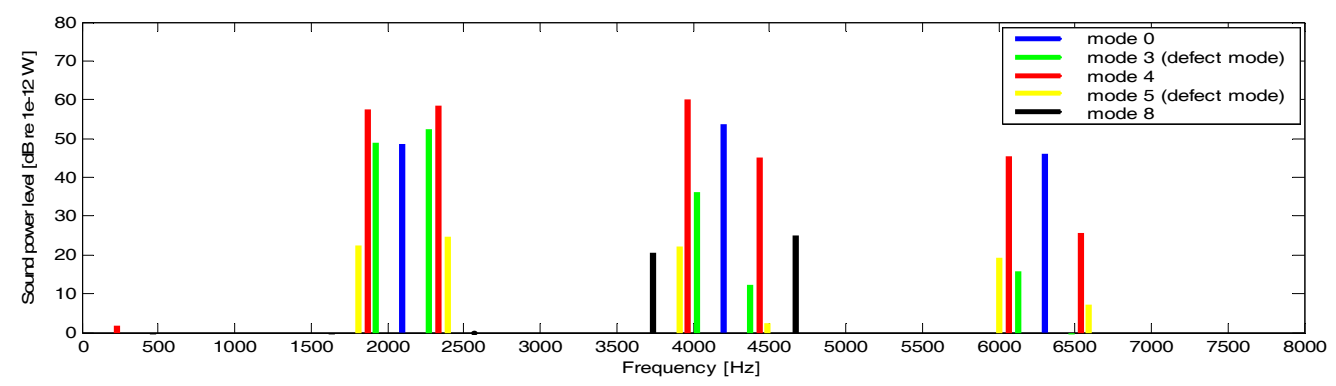

Fig. 10. Sound power level spectrum at $3500 \mathrm{rpm}$ and with $25 \%$ eccentricity

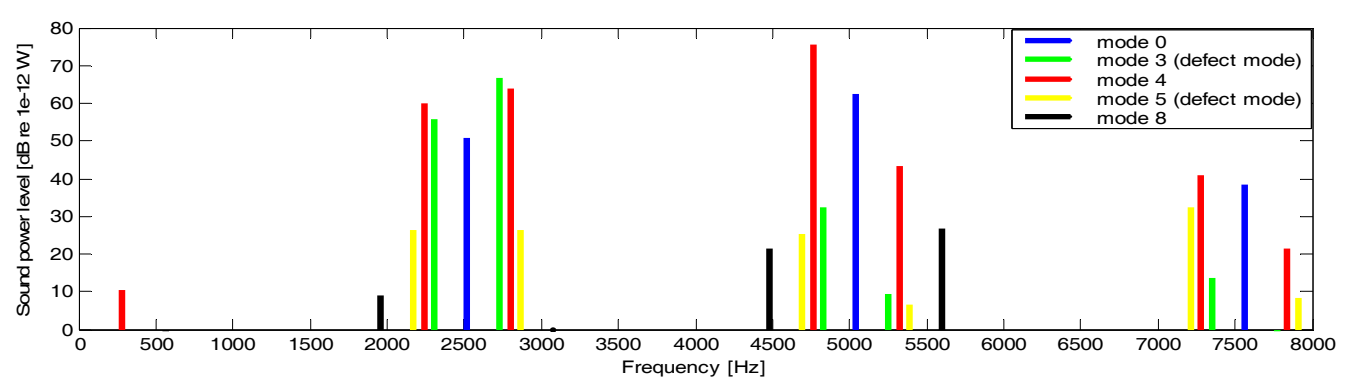

Fig. 11. Sound power level spectrum at $4200 \mathrm{rpm}$ and with $25 \%$ eccentricity

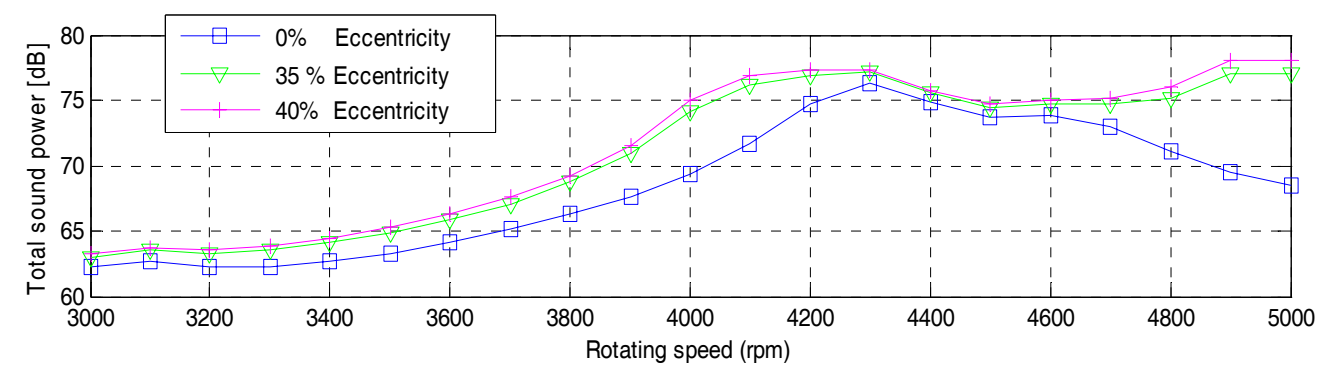

Fig. 12. Total Sound power vs rotating speed for different value of eccentricity

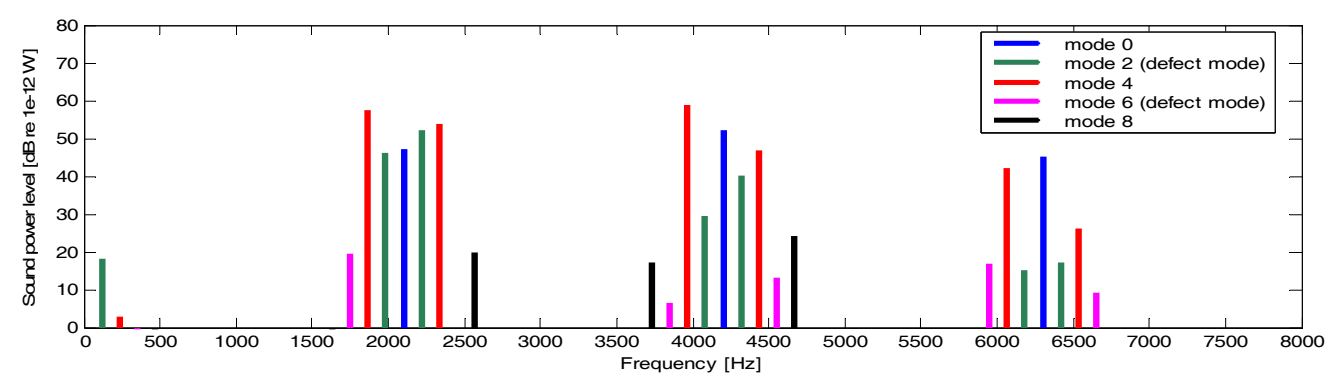

Fig. 13. Sound power level spectrum at $4200 \mathrm{rpm}$ and with partial demagnetization 


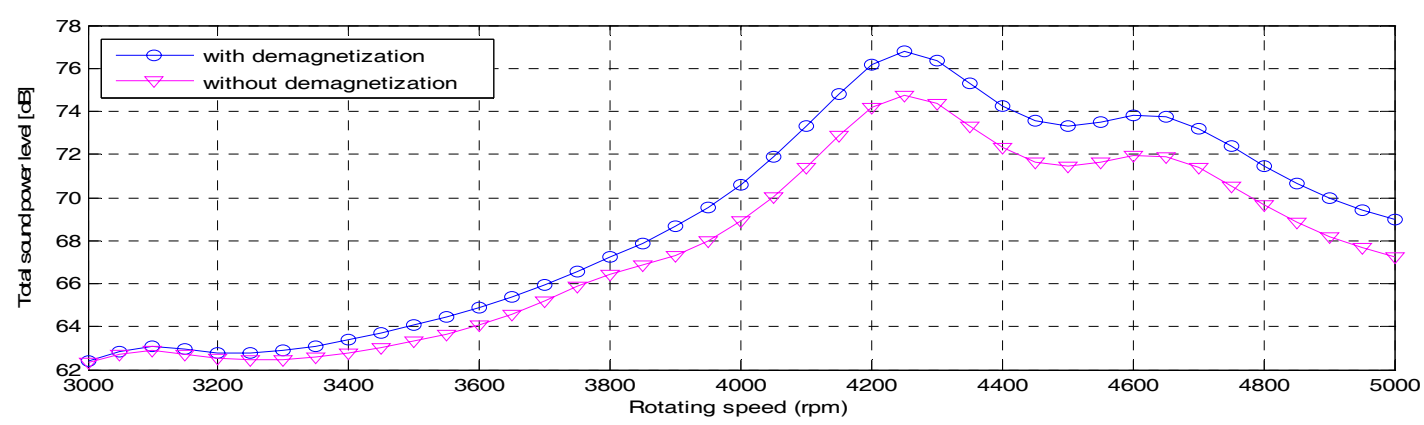

Fig. 14. Total sound power vs speed and with partial demagnetization

paring it with the symmetric case shown in Fig. 9, it was observed that partial demagnetization contributed to the generation of low mode vibration, especially mode 2, which may be very dangerous from the vibroacoustic point of view. Fig. 14 shows the variation of total sound power level vs speed, with and without demagnetization fault. In general, the demagnetization fault increased the global noise radiated from the machine, and the increase was significant for certain values of rotating speed.

\section{Conclusion}

In this paper, a noise predictive model of PM brushless motor was presented. The model took into account the effects of faults, such as eccentricity and demagnetization. The demagnetization affected the open circuit magnetic field by introducing even order harmonics, especially harmonic 2 , which created in motors mode vibration 2 . This can be very dangerous especially if the frequency of the generated force waves is near or close to the frequency of mode 2 . The eccentricity faults affect the air gap magnetic field through the permeance function. As a result, the air gap magnetic field containing other harmonic contributes to the generation of low modes of vibration. We also showed that the total sound power increased for faulty machine, and that the increase was important for certain values of rotating speed. The results are encouraging. Thus, we will consider for the remainder of this work the use of the developed model in inverse problem for detecting these defects.

\section{References}

[1] G. F Gereis, C. Wang and J. C Lai, Noise in polyphase electric motors, Taylor \& Francis, 2006.

[2] Z. Q Zhu and D. Howe, "Electromagnetic noise radiated by brushless permanent magnet DC drives", in Proceedings of sixth international conference on electrical machines and drives, Oxford, UK., September 1993.
[3] G. F Gereis, C. Wang, J. C Lai and N.Ertugrul," Analytical prediction of noise of magnetic origin produced by permanent magnet brushless motors", in Proceedings of electrical machines and drives conference IEMDC 2007, Antalya, Turkish.

[4] S. wang, M. Aydin and T. A Lipo, "Electromagnetic vibration and noise Assessment for surface mounted PM machines", IEEE Power engineering society summer meeting, Vancouver Canada, 2001.

[5] S. Rajagopolan, "detection of rotor and load faults in brushless DC motors operating under stationary and non-stationary conditions" PhD dissertation, school of electrical and computer engineering, Georgia, USA, 2006.

[6] X. Wang, Q. Li, S. Wang and Q. Li, "Analytical calculation of air gap magnetic field distribution and instantaneous characteristics of brushless DC motors", IEEE transaction on energy conversion, Vol.18, pp 425-432, 2003.

[7] Z. Q. Zhu and D. Howe, "Instantaneous magnetic field distribution in PM brushless DC motors, Part IV: magnetic field on load", IEEE transaction on magnetics, Vol 29, No, 1 January 1993.

[8] K, C. Maliti," Modelling and analysis of magnetic noise in squirrel cage induction motors", Doctoral dissertation Royal institute of technology Stockholm 2000.

[9] A. Bouchrit, S. Srairi, A. Djerdir, and A. Miraoui, "Analytical and numerical modelling of demagnetization phenomenon in a permanent magnet motor", ICEM 2004.

[10] Z. Q Zhu and D. Howe, "Improved methods for prediction of electromagnetic noise radiated by electrical machines" IEE Proc of the electric power applications, Vol.141, 1994, pp 109-120.

[11] M. P Norton and D. G Karczub, "Fundamentals of noise and vibration analysis for engineers", Cambridge, 2003. 


\section{Appendix}

Table A1. parameters of the macine

\begin{tabular}{c|c}
\hline Parameters & values \\
\hline Number of pôles & 4 \\
\hline Stator slots number & 36 \\
\hline Stator outer diameter & $165 \mathrm{~mm}$ \\
\hline Thickness of the stator frame & $28 \mathrm{~mm}$ \\
\hline Height of teeth & $20 \mathrm{~mm}$ \\
\hline Stator lamination Young modulus & $2.06^{\times} 10^{11} \mathrm{~N} / \mathrm{m}^{2}$ \\
\hline Slots opening & $3 \mathrm{~mm}$ \\
\hline Air gap thickness & $1 \mathrm{~mm}$ \\
\hline Axial length of the machine & $170 \mathrm{~mm}$ \\
\hline
\end{tabular}

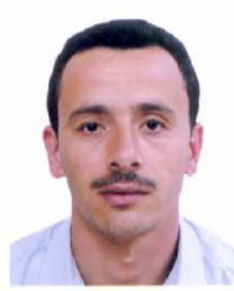

Ali Rezig received his License Diploma in Electrical Engineering from the University of Skikda, Algeria, in 1999 and his Magister Degree from the University of Jijel, Jijel Algeria, in 2002. His main research fields include vibration and noise of electrical machines, and diagnosis of electrical machines. Currently he is working on his $\mathrm{PhD}$ degree in Electrical Engineering at Batna University, Algeria

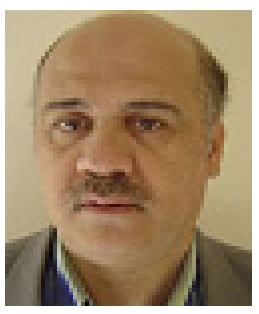

Mohamed Rachid Mekideche

After obtaining his first diploma in Electrical Engineering at the USTO University at Oran, he joined the National Polytechnicas School at Algiers in 1981 as an assistant and postgraduate student preparing for his Magister degree. He obtained the "Maître Assistant" degree in 1986. After obtaining his PhD degree from the University of Nantes (France), he became "Maître de Conferences" and then Professor. He is now working at the University of Jijel as a teacher and Dean of the Engineering Faculty. Professor Mekideche is now heading the LAMEL laboratory of the University of Jijel and is the author and co-author of about 100 works published or presented at international conferences.

\section{Djerdir}

He received his B.S. degree in Electrical Engineering from the National Institute of Electrical Engineering Bejaia, Algeria, in 1993, and his Ph.D. degree in Electrical Engineering from the University of Franche Comté Belfort, France, in 1999. Currently, he is an Associate Professor of Electrical Engineering at the Systems and Transport (SET) Laboratory at University of Technology Belfort-Montbéliard, France. He has been supervising scientific research since December 2007. His research interests include modelling and design of electric vehicle systems (electrical machines, energy storage devices, and power converters). Since 2005, he has developed his main works on the availability and high efficiency of electric drive trains in the transport area by combining the experimental and theoretical approaches. 